\title{
11 Septiembre de 1973: Incomprensiones y ambigüedades entre la DC
}

\author{
Chilena y la Italiana ${ }^{1}$
}

\section{September 1973: Misunderstandings and ambiguities between DC and Chilean Italian}

Raffaele Nocera ${ }^{2}$

Los estudiosos que se han ocupado de las relaciones entre Chile e Italia desde la segunda mitad del siglo XX, frecuentemente han tenido que lidiar con las presuntas o acertadas analogías entre el sistema político chileno y el italiano. Esta clave interpretativa inició con la elección de Eduardo Frei Montalva, del Partido Demócrata Cristiano de Chile (PDC) ${ }^{3}$, a la Presidencia de la República en 1964, para fortalecerse durante los años de la Unidad Popular y en el período inmediatamente sucesivo al golpe ${ }^{4}$. Por otra parte, si a partir de los años sesenta y hasta el final de la decada posterior "America Latina adquiere, en Italia, una gran importancia", son justamente "los acontecimientos chilenos los que ocupan un lugar de absoluta relevancia en el debate político y cultural" $"$. Es, además, ampliamente conocida la reflexión hecha por el secretario del partido comunista italiano (PCI) Enrico Berlinguer a partir de la llamada "lección chilena", reflexión que inspiró la estrategia política elaborada y apoyada por los comunistas italianos, conocida como "el compromiso histórico"6.

\footnotetext{
1 Este artículo es el producto de la investigación realizada en el marco del proyecto "Inserción Internacional de la Democracia Cristiana chilena 1973-1989", № 1130046. CONICYT-FONDECYT regular. Se agradece a FONDECYT por la financiación aportada.

2 Università di Napoli “L’Orientale” - rnocera@unior.it

${ }^{3}$ Acerca del PDC véase Michael Fleet, The Rise and Fall of Chilean Christian Democracy, Princeton, Princeton University Press, 1985, e Wilhelm Hofmeister, La opción por la democracia. Democracia Cristiana y desarrollo político en Chile, 1964-1994, Santiago de Chile, Konrad Adenauer Stiftung, 1995. Sobre Eduardo Frei Montalva, cfr. los dos volúmenes de Cristián Gazmuri, Eduardo Frei Montalva y su época, Santiago, Aguilar, 2000. Finalmente, véase Scott Mainwaring - Timothy R. Scully (eds.), La democracia cristiana en América Latina, México, Fondo de Cultura Económica, 2010, un estudio comparativo de corte político sobre la Democracia Cristiana en America Latina.

${ }^{4}$ El origen de una presunta analogía entre el Chile de la UP y la situación política italiana de los primeros años Setenta se debe al famoso artículo de Cyrus Sulzberger, "Spaghetti with Chile Sauce", New York Times, 13 de enero de 1971.

${ }^{5}$ Luigi Guarnieri - Maria Rosaria Stabili, "Il mito politico dell'America Latina negli anni Sessanta e Settanta", en Agostino Giovagnoli - Giorgio Del Zanna (a cargo de), Il mondo visto dall'Italia, Milano, Guerini e Associati, 2004, p. 228. Con respecto a las analogías del punto de vista de las dinámicas políticopartidistas, estos dos autores señalan, además, que "con la victoria electoral de la Unidad Popular y la presidencia de Allende [...] en el sistema de partidos chileno, el italiano se refleja plenamente y nuestros tres partidos de masa (demócrata-cristiano, socialista y comunista) registran antiguas solidaridades con sus correspondientes chilenos" (p. 235).

${ }^{6}$ Cfr. Andrea Mulas, Il Cile di Allende e la politica italiana: il compromesso storico, San Cesario di Lecce, Manni, 2005; Alessandro Santoni, “Berlinguer, il compromesso storico e il caso cileno", Contemporanea, 3, julio de 2007, pp. 419-439, Il PCI e i giorni del Cile, Roma, Carocci, 2008, "Los comunistas italianos y el Partido Comunista de Chile en la década de los 60", en Olga Ulianova (ed.), Redes Políticas y militancias,
} 
En cambio, han sido menos analizadas las analogías entre las otras dos principales formaciones políticas de aquel período de ambos Países, es decir la Democracia Cristiana italiana (DCI) y la chilena ${ }^{7}$. Este artículo propone algunas reflexiones acerca de la recepción de los acontecimientos chilenos y sobre las contradicciones que caracterizaron la conducta del partido de mayoría relativa en Italia ${ }^{8}$, puesto en jaque por sus responsabilidades y por las divisiones de la democracia cristiana chilena en ocasión del golpe de estado de $1973^{9}$. En relación directa con este problema, analizaremos la falta de reconocimento de la junta militar por parte de Italia. Sin embargo, es preciso especificar que estas dos temáticas se analizan principalmente en las semanas inmediatamente sucesivas a la conquista del poder por parte de los militares golpistas.

\section{El golpe}

En cuanto las noticias del Golpe se difundieron en Italia, todas las fuerzas políticas representadas en el Parlamento - con la sola excepción del Movimento Sociale Italiano (MSI), partido heredero del fascismo - condenaron sin vacilar el golpe de Estado en Chile. Sin embargo, la posición de la DCI fue mucho más compleja y delicada, como lo evidencian la prensa de inspiración Demócrata Cristiana ${ }^{10}$, los comunicados y las declaraciones oficiales de los principales representantes del partido.

El primer comentario relevante fue el de Amintore Fanfani, quien expresaba sus condolencias por la muerte de Salvador Allende y condenaba el uso de la fuerza que, aunque se utilizara con el objetivo de restaurar el orden perdido, en realidad había pisoteado la libertad $^{11}$. El secretario nacional había decidido hacer esta declaración 24 horas antes, como se evidencia en el texto escrito en su diario:

Santiago, Universidad de Santiago, 2009, pp. 313-354, y "Il Cile e il travaglio identitario del comunismo italiano", en Raffaele Nocera - Claudio Rolle Cruz (a cura di), Settantré. Cile e Italia, destini incrociati, Napoli, Think Thanks, 2010, pp. 167-189. Véase finalmente, el reciente ensayo de Valentine Lomellini, "Bisbigliando al «nemico»? Il Pci alla svolta del 1973, tra nuove strategie verso Washington e tradizionale anti-americanismo", Ricerche di Storia Politica, n. 1/2013, pp. 25-44.

${ }^{7}$ Sobre esta temática, y acerca de los vínculos entre los dos partidos desde el principio de los años sesenta que no es posible abarcar en esta ocasión, me permito sugerir mis obras: "Dove non osò la diplomazia. Alcune riflessioni sull'internazionalismo democristiano e sulle relazioni italo-cilene, 1962-1970", Ricerche di Storia Politica, n. 1/2009, pp. 29-52; "Las relaciones diplomáticas y político partidistas ítalo-chilenas durante el gobierno de Eduardo Frei Montalva”, Historia, n. 42, vol. II, julio-diciembre de 2009, pp. 435470.

${ }^{8}$ Hasta 1992 el sistema de los partidos en Italia fue caracterizado por un pluralismo polarizado, con dos partidos principales (DCI y Partido comunista, PCI) que no alcanzaban la mayoría. La DCI, con excepción de las elecciones europeas de 1984, siempre fue el partido más votado y, por consecuencia, el que detenía la mayoría relativa.

${ }^{9}$ Hay que tener en cuenta que la única referencia al golpe de Estado del 1973 que aparece en la Storia della Democrazia Cristiana a cargo de Francesco Malgeri es la consideración que el compromiso histórico fue, además, la respuesta del PCI "a las preocupaciones provocadas en Italia por la experiencia de Allende, experiencia que también por su maximalismo y su veleitarismo no había sido capaz de vencer el golpe de derecha del general Pinochet" (Pierluigi Castellani, "La Democrazia Cristiana dal centro-sinistra al delitto Moro (1962-1978)", vol. IV, Dal centro sinistra agli “anni di piombo" (1962-1978), Roma, Edizioni Cinque Lune, 1989, p. 73). Sobre las "consecuencias" de la lección chilena para la DCI véase Agostino Giovagnoli, Il partito italiano. La Democrazia cristiana dal 1942 al 1994, Roma-Bari, Laterza, 1996, pp. 155-156.

${ }^{10}$ Una reflexión sobre la lectura del golpe de Estado en la prensa de área católica la encontramos en Chiara Brunetti, "La stampa cattolica e il golpe cileno", en Raffaele Nocera - Claudio Rolle Cruz (a cura di), Settantré. Cile e Italia, cit. pp. 25-54.

11 "Non si restaura l'ordine calpestando la libertà", Il Popolo, 13 de septiembre de 1973. 
"Con respecto al Golpe en Chile, condeno con reiteración la presencia de la violencia en la vida política [...] Aconteció lo que yo predije en junio a Valdés, cuando él vino a verme al Senado ${ }^{12}$ : es decir, que el hecho de invitar a los militares a participar en el gobierno de Allende, acabaría por convencerlos que tenían que tomar el poder y prescindir de los civiles. Él no creyó en mi predicción que, lamentablemente, se cumplió!"13.

Dicha reflexión subraya el hecho de que Allende no había fallado en las transformaciones socio-económicas realizadas por el ejecutivo, sino en la incorporación de los militares en el equipo gubernamental.

El 13 de septiembre también es el día en el que toda la prensa italiana decidió dar amplio espacio a los hechos chilenos. Il Popolo, diario oficial de la DCI, publicó un artículo en primera página en el que pronosticaba que los militares chilenos tenían la intención de formar un ejecutivo "de tipo brasileño", que "se mantuviese en el poder durante mucho tiempo"14. Además en la página 3, también dedicada completamente a Chile, se publicaba un artículo en el que se anticipaba una constante de los meses siguientes: es decir, se proponía una visión muy positiva del líder socialista ${ }^{15}$, pero crítica hacia la acción del gobierno y de los partidos de izquierda ${ }^{16}$.

Al día siguiente, Il Popolo publicaba, integralmente, el documento difundido dos días antes por la dirección nacional del PDC con el que se apoyaba la acción de las Fuerzas Armadas, señalando como único responsable "del desastre económico, del caos institucional, de la violencia armada" al gobierno de Allende ${ }^{17}$. Sin embargo, el diario adjuntaba un comunicado muy crítico de la DCI, en el que se tomaba sustancial distancia de la línea adoptada por los homólogos chilenos.

"Consideramos que - y ésta es nuestra única respuesta a todos los intentos de involucrar a la DC italiana en los eventos chilenos - no existen entre los partidos de

\footnotetext{
12 Gabriel Valdés había estado en Italia para participar, junto a Frei, al XII congreso de la DCI, realizado en Roma del 6 al 10 de junio de 1973. Valdés ha dejado los recuerdos de su actividad política en la biografía Gabriel Valdés, Sueños y memorias, Santiago, Taurus, 2009 (véanse, sobre todo las págg. 117-197 sobre su experiencia de ministro de Relaciones Exteriores de 1964 a 1970 durante el gobierno de Frei). Ver también el libro de Elizabeth Subercaseaux, Gabriel Valdés, señales de historia, Santiago, Aguilar, 1998.

${ }^{13}$ Archivio Storico del Senato della Repubblica (desde ahora ASSR), Fondo Fanfani, Diario, 12 de septiembre de 1973.

14 "Insurrezione cilena contro i militari. Si combatte nelle strade di Santiago", Il Popolo, 13 de septiembre de 1973.

15 Sobre la trayectoria política y personal de Allende cfr. el reciente trabajo de Mario Amorós, Allende. La biografía, Barcelona, Ediciones B, 2013.

16 "Allende. Piena coerenza di una scelta", Il Popolo, 13 de septiembre de 1973. Merece la pena señalar que, los juicios emanados en los tres años anteriores, fueron a menudo de tono muy diferente. En la revista trimestral dirigida por Angelo Bernassola (D.C. Internazionale. Notizie, documentazioni e commenti sulla presenza dei democristiani nel mondo), en aquel entonces responsable de la "Sezione Esteri della Direzione centrale" de la DCI, Angelo Sferrazza describía a Allende como un "hombre proveniente de una rica familia y él mismo, rico, masón y de formación cultural laica y burguesa", empujado por el extremismo de la izquierda marxista, "adulada y protegida" por él, sobre el "camino de la demagogia" ("Speciale Cile", n. 23/72, marzo-octubre de 1972, p. 4). Pero véase también, como ejemplo entre los más significativos, el artículo, siempre titulado "Allende fa bancarotta" escrito poco antes del golpe y publicado en las páginas de La Discussione, semanal fundado por Alcide De Gasperi (13 de septiembre de 1973, n. 35, pp. 15-16).

${ }^{17}$ El comunicado se encuentra en Jorge Donoso Pacheco (comp.), Tomic, testimonios, Santiago, Editorial Emisión, 1988, p. 467, y en Eugenio Ortega Frei, Historia de una alianza, Santiago, CED-CESOC, 1992, pp. 42-43.
} 
inspiración cristiana [...] vínculos que disminuyan, condicionen o limiten la libertad de decisión frente a los problemas del País en el que cada partido actúa. [...] mientras reconozcamos al partido de los demócratacristianos chilenos el derecho de defender su propia conducta y su propia línea política, criticando aquella de sus adversarios [...] creemos poder atribuir a la DC italiana el derecho de decir que [...] la expresión de simple "pesar" no nos parece adecuada a la gravedad de los hechos. Además, es difícil comprender cómo se pasa de la realidad de una violenta interrupción del proceso democrático-constitucional, que también la DC chilena hasta tres días antes apoyaba como el único correcto, a la optimista espera del desarrollo de una intervención, que la DC italiana [...] condena",18.

Con esta declaración, la DCI mostraba su desacuerdo (y desorientación) con respecto a la posición asumida por el PDC, además de ser forzada a hacer marcha atrás en relación a lo establecido dos días antes, cuando su órgano oficial, al dar por primera vez las noticias del golpe de Estado, había subrayado que el partido chileno estaba trabajando en un acuerdo con el gobierno ${ }^{19}$.

Fue Fanfani quien estableció la línea del partido; de hecho, el día antes había apuntado en su diario:

"La DC chilena hace un comunicado muy servicial sobre los jefes chilenos. Hago escribir un comentario desde el "Popolo", también contra las izquierdas italianas que tienden a confundir los jefes chilenos con la DC italiana. Es verdad que las pespectivas empeoran y no será fácil volver al sistema democrático ni siquiera en Chile. La DC de allá terminará por dividirse" 20 .

La posición asumida por Fanfani fue apreciada por muchos exponentes de la izquierda demócrata-cristiana chilena (minoría del partido en ese momento); entre ellos Gabriel Valdés, que dos semanas después escribió una larga carta al secretario nacional de la DC italiana, en la que le agradecía las declaraciones sobre el golpe de Estado, ya que representaban "un llamado estricto y necesario al respeto de los principios que dan vida a la esencia misma de la Democracia Cristiana" ${ }^{21}$. Aunque admitiera las responsabilidades de Allende y lamentara la muerte del diálogo y la pérdida de una oportunidad preciosa - tal vez única - para llegar a un "acuerdo constructivo, si bien muy difícil y complejo, en Chile, entre cristianos y marxistas", la desaprobación del ex ministro de Relaciones Exteriores por la acción de sus compañeros de partido resultaba sin contemplación:

"La tesis de los dirigentes más fuertes del Partido era que la U.P. llevaría el País a la dictadura marxista y entonces, cuanto antes se interrumpiera de alguna manera la vida del Gobierno, tanto antes el País regresaría a la normalidad y con un gasto relativamente menor en vidas humanas y capacidad económica. Su tesis era ésta: los militares como solución inmediata, y la D.C. a largo plazo. [...] Considero que aquellos que tienen una

\footnotetext{
18 Il Popolo, 14 de septiembre de 1973.

${ }^{19}$ Cfr. F.A., "Democrazia in pericolo", Il Popolo, 12 de septiembre de 1973.

${ }^{20}$ ASSR, Fondo Fanfani, Diario, 13 de septiembre de 1973

${ }^{21}$ Carta de Gabriel Valdés a Amintore Fanfani, 25 de septiembre de 1973, Archivo Histórico Gabriel Valdés (de ahora en adelante AHGV) consultable, como todos los otros documentos de este archivo, en www.ahgv.cl.
} 
influencia decisiva en el Partido han perseguido una estrategia equivocada y funesta para la D.C. chilena [...] El partido, siempre con mayores dificultades, tendrá que explicar su aprobación del golpe de estado, la seguidilla de abusos y persecuciones de personas e ideas y la - hasta ahora - clara ostentación totalitaria de su política"22.

Valdés, quien estaba viviendo en Estados Unidos a cargo del PNUD, dos semanas después del 11 de septiembre, probablemente ya estaba al corriente de las tentativas puestas en marcha por Frei, Aylwin y otros, para romper las perplejidadades surgidas entre los amigos del PDC fuera de Chile. Operación, esta última, que ofuscaba la reputación que en pocos años habían ganado a nivel internacional los demócrata-cristianos chilenos, puesto que implicaba la aceptación de las motivaciones esgrimidas por las Fuerzas Armadas para justificar su intervención, entre las cuales la existencia de un arsenal a disposición de los "marxistas" con el objetivo de realizar un autogolpe ${ }^{23}$. Como se evidencia más adelante, la línea seguida por los vértices de la DC se basaba en la apreciación que los militares no conservarían el poder durante largo tiempo y que, para asegurar la gobernabildiad del País, necesitarían el PDC o sus especialistas y líderes como fuerza política ${ }^{24}$.

A la toma de posición de la dirección nacional del 12 de septiembre, hizo eco, así, un documento del Departamento Internacional dirigido a los "Partidos demócrata-cristianos y a personalidades mundiales", con el intento de ofrecer "una información objetiva sobre la realidad y los acontecimientos políticos" vividos en Chile en aquellos días. Se sostenía que la Junta Militar "con razón [...] debió actuar forzada por las circunstancias de un País al borde de la guerra civil", y que los primeros comunicados tenían el objetivo de "unir a la familia chilena, reconstruir el País, normalizar la vida ciudadana y prolongar su presencia en el poder sólo hasta el logro de estos objetivos"; y se añadía y se ponía especial énfasis en el hecho de que los demócrata-cristianos habían intentado con todos los medios de evitar la solución de la fuerza. El texto intentaba, principalmente, ratificar el juicio manifestado el día después del golpe, para invalidar las críticas expresadas en Chile y en el exterior ${ }^{25}$.

Estos argumentos no modificaron, al menos en un principio, la posición asumida por la DCI. Si bien con tonos más blandos, ella continuó criticando la acción del partido chileno, y añadió como nuevo elemento de reflexión, la existencia de divisiones y divergencias en su interior - que el documento mencionado desmentiría algunos días después - y de la "rígida

\footnotetext{
22 AHGV, Carta de Gabriel Valdés a Amintore Fanfani, 25 de septiembre de 1973.

${ }^{23}$ Se hace referencia al llamado Plan $Z$ del cual no hay noticias en los primeros comunicados oficiales emitidos por la junta militar (cfr. Corrado Corghi, L'ideologia democristiana e l'internazionale DC, Milano, Mazzotta, 1974, pp. 205-206). Hay que poner en evidencia el gran impacto que causó, entre los DC italianos, la entrevista a Eduardo Frei Montalva, publicada en el diario español $A B C$ el 10 de octubre de 1973, que planteaba el papel salvador de las FFAA. Si bien el propio Frei desmintió la entrevista y expresó una protesta formal al $\mathrm{ABC}$, su reproducción en Europa y en Chile, dejaron marcado lo que amplios sectores de la opinión pública internacional vieron como la postura del PDC chileno frente al golpe. Muchos fragmentos de la entrevista en Franca Bertolini - Frieda Hermans, La DC in Cile, Milano, Mazzotta, 1974, pp. 210-213. Los militares golpistas denunciaron la existencia de armas de diferente tipo disponibles para el autogolpe de la U.P. en el Libro Blanco publicado en noviembre de 1973 (cfr. "Il discorso di Tomic nella riunione del partito democratico cristiano due mesi dopo il golpe", in Pino Di Salvo (a cura di), Cile. Una lezione. Documenti della sinistra democristiana cilena, Roma, La Tartaruga, 1974 pp. 277-280). Cfr. finalmente "Aylwin: le "sinistre" preparavano un golpe", Il Popolo, 19 de septiembre de 1973.

${ }^{24}$ Veinticinco años después, Aylwin hacía finalmente una autocrítica a las opiniones emanadas y a las posiciones tomadas en ocasión del golpe de Estado, reconosciendo también lo infundado de una "insurrección de la extrema izquierda" (Patricio Aylwin Azócar, El reencuentro de los Demócratas. Del Golpe al Triunfo del NO, Santiago, Ediciones B, 1998, p. 14).

${ }^{25}$ AHGV, Carta Demócrata Cristiana desde Chile, n. 20, 24 de septiembre de 1973.
} 
contraposición de dos actitudes", una atribuida a Patricio Aylwin y favorable al diálogo con los militares, porque éstos últimos iban a regresar muy pronto a sus cuarteles; otra a Radomiro Tomic "de claro rechazo" ${ }^{26}$. Así actuando, la DCI decidía no alinearse con la Unión Mundial Demócrata Cristiana (UMDC) ${ }^{27}$ y con la Organización Demócrata Cristiana de América (ODCA) que con sus declaraciones oficiales en relación al Golpe (respectivamente del 13 y del 15 de septiembre) se habían preocupado mucho de no condenar la actitud de los demócrata-cristianos chilenos ${ }^{28}$. La posición asumida por los italianos, y por Fanfani en particular, de hecho, no resultaba ni dada por supuesta ni libre de repercusiones internas, si se consideran los cargos de algunos de los más distinguidos exponentes en los organismos internacionales de la DC, primero entre ellos, Mariano Rumor, presidente de la UMDC. Y por cierto, los chilenos no ofrecieron ninguna solución ${ }^{29}$, sino que se mostraron más bien preocupados por la sobrevivencia del partido y por negociar una especie de colaboración externa con los militares. Quien condujo y trató a hurtadillas con los golpistas, fue principalmente el presidente Aylwin, que en una carta a Valdés, le informaba de una reunión con la junta ${ }^{30}$, y admitía que su "principal preocupación" era, esencialmente "la unidad demócrata-cristiana para el futuro":

“Creo que llegará la hora del restablecimiento democrático y entonces nosotros tendremos posibilidades reales si no nos hemos atomizados por diferencias que siembren la discordia en nuestros cuadros y confundan a nuestras bases. Por ahora,

26 "I d.c. cileni divisi da "serie divergenze"”, Il Popolo, 15 de septiembre de 1973. Sobre el asunto el órgano del partido insistía también en los días siguientes. Para citar otro ejemplo véase "Continua in tutto il Cile la repressione militare" (Il Popolo, 18 de septiembre 1973) en el cual se publicaban partes de una entrevista realizada por Tomic a la oficina de correspondencia de la agencia de prensa Inter Press Service de Buenos Aires donde no se compartía la declaración emanada el 12 de septiembre por Aylwin porque resultado de una "apurada e unilateral decisión del vértice".

${ }^{27}$ La UMDC fue constituida durante la III Conferencia intercontinental de los demócrata cristianos realizada en Santiago de Chile desde el 27 al 30 de julio de 1961. Cfr. Roberto Papini, L'Internazionale DC. La cooperazione tra i partiti democratici cristiani dal 1925 al 1985, Milano, Franco Angeli, 1986, pp. 33-72, y Niels Arbøl, I democristiani nel mondo, Milano, Edizioni Paoline, 1990, pp. 62-68.

${ }^{28}$ Las declaraciones en Roberto Papini, L'Internazionale DC. La cooperazione tra i partiti democratici cristiani dal 1925 al 1985, cit. p. 274, nota 99. La línea del órgano DC de América Latina tampoco cambiaría más adelante. Durante el VIII Congreso realizado en Curaçao en 1974, éste acogió, de hecho, la relación sobre la evolución política nacional presentada por la delegación chilena, donde, si bien con matices menos duros, se reiteraban las acusaciones al gobierno de Allende y la total extraneidad al golpe. Con respecto a la declaración del 12 de septiembre de 1973, los demócratas chilenos evitaban únicamente justificar el golpe y lo hecho por las Fuerzas Armadas en el primer año de gobierno. Cfr. Informe chileno, VIII Congreso de la ODCA en Curaçao, agosto 30 - 1 de septiembre de 1974, documento custodiado pero no catalogado por el archivo de la Corporación Justicia y Democracia. Analizando bien, se trataba de una elección obligada, ya que su relación se presentaba solo algunos meses después de la "Declaración de Principios" emitida por la junta de gobierno (marzo de 1974) y con la cual los militares manifestaban su propósito de quedarse "indefinidamente" en el poder.

${ }^{29}$ Después del documento del día siguiente al golpe, la dirección nacional emitió otros dos comunicados, mucho más largos y articulados y menos condescendientes hacia la junta militar, sobre todo en materia de violación de los derechos humanos (en el cual sin embargo se confirmaba el juicio expresado el día después del golpe sobre la responsabilidad de la Unidad Popular). Véanse, "Posición del PDC frente a nueva situación del país", 27 de septiembre de 1973 y Patricio Aylwin Azócar, "Informe sobre posición de la Democracia Cristiana chilena frente al gobierno de S. Allende", noviembre de 1973, ambos en Centro de documentación Fundación Frei, desde ahora CFF, respectivamente PPdc-PP-8 e PPdc-PP-9.

${ }^{30}$ En la carta Aylwin sostenía que la junta los había recibido el día diez de octubre, señalando también que "por insinuación expresada en varios recados, pedimos audiencia a fin de tratar del régimen de los Partidos Políticos" (AHGV, Carta de Patricio Aylwin a Gabriel Valdés, 16 de octubre de 1973). 
pienso que nuestra actitud debe ser de no comprometerse políticamente; pero no negar nuestra cooperación - la de gente nuestra - en lo técnico y administrativo"31.

La respuesta del ex ministro de Relaciones Exteriores no se hizo esperar. Sin atribuirle explícitamente responsabilidades directas y reconociendo los errores cometidos por la U.P., censuraba duramente la acción del partido y, sobre todo, las principales argumentaciones usadas por el mismo Aylwin y por los otros líderes de primer orden. El texto merece ser citado en algunos pasajes porque es indicativo de las fuertes divergencias que se registraron en aquellos días al interior del PDC con respecto al golpe de Estado, y de la diferente percepción que tuvieron los dirigentes en Chile y aquellos que estaban en el exterior, en relación a la "misión como DC".

"Para salvar el cuerpo o el poder, o la posibilidad del poder, hemos ido perdiendo el alma $[\ldots]$ DC y dictadura son esencialmente opuestos. La imagen nuestra fuera es atroz y no solo por obra de los marxistas. Leer las declaraciones de Eduardo F. comentadas en todas partes negativamente - por decir lo menos - quitan toda esperanza en la posibilidad de recuperación. Seguir denigrando a Allende lo considero deshonesto. Estamos en presencia de un fascismo que no podemos negar y que nos aplastará. Seguir justificándolo - y algunos aplaudiendo - con el argumento que la U.P. había producido el caos y que quería una dictadura no tiene justificación. En fin, tú conosces mejor los hechos pero desde fuera se ve el porqué. El clamor que la revolución ha levantado en todo el mundo es atroz. Que la Junta dé sus explicaciones es natural, pero que la DC avale lo que sucede y nos convirtamos en abogados me resulta intolerable" ${ }^{32}$.

¿Y la DC italiana? No cabe duda en que la querelle propia de los demócrata-cristianos chilenos causó cierta vergüenza, obligándola a valerse de cualquier pretexto. A pesar de lo anterior, a partir de mediados del mes de septiembre, ella pareció mucho más interesada en detener los golpes enviados por los partidos de izquierda, que la acusaban de complicidad con lo acontecido en Chile y de distraer la atención de la opinión pública. Así se explica que, hasta el debate en el Parlamento del 26 de septiembre, haya sido cada vez mayor, la insistencia de la relación entre el golpe chileno y el "empeoramiento de la persecución contra los intelectuales soviéticos" (la referencia era en particular a los casos Sakharov y Solgenitsin $)^{33}$.

\section{Sin una posición común sobre los acontecimientos chilenos}

Hay que subrayar, de todos modos, que a partir del 18 de septiembre y en previsión de la discusión en la Cámara de Diputados, la DCI también comenzó a modificar parcialmente el juicio sobre los colegas chilenos y a insistir, cada vez más, en las responsabilidades de la U.P. En ese sentido, son emblemáticos el mini reportaje con el título "La lección de Chile" escrito

\footnotetext{
31 Ibid.

32 AHGV, Carta de Gabriel Valdés a Patricio Aylwin, 19 de octubre de 1973.

33 Véanse, solo para citar dos ejemplos, las declaraciones de Fanfani y de Flaminio Piccoli, presidente del grupo parlamentario a la Camara de Diputados, publicadas en primera página en Il Popolo el 16 de septiembre, respectivamente en "Coerente impegno per la libertà e il progresso" y "Presentate interpellanze del gruppo dc alla Camera".
} 
por Marcello Gilmozzi y publicado por Il Popolo en los días 20-23 de septiembre ${ }^{34}$; y las palabras del director Franco Amadini, según el cual "recordar los errores cometidos por el gobierno, no significa justificar su violenta destitución"35. Sin embargo, es verdad que al interior de la DCI se enfrentaron posiciones opuestas sobre los hechos chilenos, reflejo de las varias corrientes y almas presentes en el partido. Así, solo por citar algunos ejemplos, mostraron desaprobación Antonio Bisaglia, exponente de punta de los demócrata-cristianos del norte del País, según el cual "también hubo algunas responsabilidades por parte de la oposición"36, y el Subsecretario de Relaciones Exteriores Luigi Granelli, para quien era un deber expresar solidariedad "con quienes en Chile [...] rechazan la idea de los que creen que

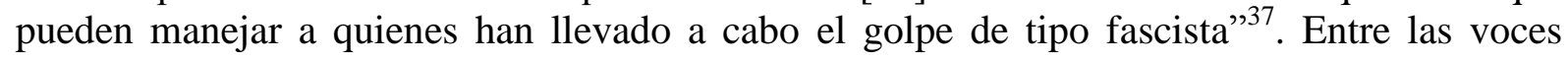
críticas, se destacó la de Carlo Donat Cattin, líder de la corriente interna de izquierda "Fuerzas Nuevas": aludiendo a la posición asumida por los demócrata-cristianos chilenos del mencionado grupo "disidente" ${ }^{38}$ (al que pertenecían Renán Fuentealba, Bernardo Leighton y Radomiro Tomic) $)^{39}$, acusó a la DC chilena de haber participado "a tientas" en el golpe de Estado $^{40}$. En el bando opuesto estuvieron otros destacados líderes, como Giulio Andreotti, quien el 26 de septiembre, anticipando la publicación en las páginas de Concretezza de una declaración enviada casi un mes antes por Aylwin al movimiento mundial demócratacristiano, invitó por aquellos días a no emitir "juicios demasiado fáciles" sobre los acontecimientos de Chile. Pero, de hecho, en la revista dirigida por Andreotti, él no se mostró para nada cauteloso. A pesar de censurar el uso de la violencia como método de lucha política, declaraba su convicción sobre la completa extraneidad del PDC en el golpe de Estado y confiaba en "una rápida evolución de esta paréntesis de fuerza"41.

En defensa del PDC también estuvo Piccoli ${ }^{42}$, quien por otro lado fue uno de los primeros del partido en hacer referencia explícita a las repercusiones que el golpe iba a tener en el debate y en la vida política italiana ${ }^{43}$. Estando así las cosas, en el debate que se desarrolló en el Parlamento sobre los acontecimientos chilenos ${ }^{44}$ para el partido de mayoría relativa italiano, no fue fácil definir qué conducta asumir, tanto más que en esos días la revista Politica

\footnotetext{
${ }^{34}$ Se trató de cuatro largos artículos titulados "Tutti i "segnali" indicavano pericolo", "Disperazione e speranza", "Rivoluzione e produzione", "Il "golpe" è contro la democrazia" (Marcello Gilmozzi, Il Popolo, respectivamente, 20, 21, 22, 23 de septiembre de 1973).

35 Franco Amadini, "La nostra coerenza democratica", Il Popolo, 18 de septiembre de 1973.

36 "Condanna politica e morale delle violenze consumate in Cile", Il Popolo, 19 de septiembre de 1973.

37 "Su "golpe" cileno e dissenso in URSS dibattito alla Camera", Il Popolo, 20 de septiembre de 1973.

${ }^{38}$ Cfr. "Declaración disidente: 13 de septiembre 1973", en Jorge Donoso Pacheco (comp.), Tomic, testimonios, Santiago, Editorial Emisión, 1988, p. 467-469. Véase también Cristián Gazmuri, Eduardo Frei Montalva y su época, $2^{\circ}$ vol., cit. pp. 856-857; y el más reciente Jorge Donoso Pacheco - Grace Dunlop Echavarría, Los 13 del 13. Los DC contra el golpe, Santiago, RIL Editores, 2013.

${ }^{39}$ Según Tomic la declaración del 12 de septiembre fue "inútilmente precipitada [...] implicó un imprudente aval al golpe en un momento en que hubiera sido mejor quedarse callado: fue, en definitiva, un serio error político" "Il discorso di Tomic nella riunione del partito democratico cristiano due mesi dopo il golpe", in Pino Di Salvo (a cargo de), Cile. Una lezione. Documenti della sinistra democristiana cilena, Roma, La Tartaruga, 1974, p. 283).

${ }^{40}$ Luigi Guarnieri - Maria Rosaria Stabili, "Il mito politico dell'America Latina negli anni Sessanta e Settanta", cit. p. 239.

41 Giulio Andreotti, "Un documento cileno", Concretezza, n. 19, 1 de octubre de 1973, p. 4. Hay que tener en cuenta que Andreotti recibió el documento del responsable de la Oficina internacional del PDC Enrique Krauss Rusque con fecha 28 de agosto.

42 Flaminio Piccoli (1915-2000) fue uno de los principales representantes de la DC italiana, diputado desde 1958 hasta 1992, y después senador hasta 1994.

43 "Piccoli: evitare in Italia gli errori commessi nel Cile", Il Popolo 18 de septiembre de 1973.

${ }^{44}$ Atti parlamentari, Camera dei Deputati, VI Legislatura, 1973, Sesión del 26 de septiembre, pp. 91499189. Partes del debate se encuentran en "L'Italia e il "golpe" cileno. Dibattito alla Camera dei Deputati. Moro illustra la posizione del governo", Relazioni Internazionali, n. 40, 6 de octubre de 1973, pp. 10251032; para un comentario véase Ellio Rogati, "La tragedia cilena a Montecitorio" (p. 1001).
} 
Internazionale escribió que en el centro del debate político italiano estaba el problema de la relación entre la línea de la DC italiana y la chilena:

“Podría la DC italiana haber alentado con el ejemplo y tal vez con las palabras a los demócratas cristianos chilenos a exasperar su posición hasta la ruptura, con el objetivo de utilizar un impulso hacia la derecha para alcanzar el poder?"45.

Dicha hipótesis, si confirmada, podía provocar un grave desconcierto en la DCI. Probablemente y para disipar toda sospecha, la línea oficial asumida por el partido, fue aquella de una condena "dura y sin justificación" del golpe de Estado, pero en el cuadro de "un análisis despiadado de las contradicciones internas del gobierno de la Unidad Popular y de su incapacidad de gobernar las tensiones sociales" ". En la Cámara de Diputados, además, Piccoli minimizó la responsabilidad de los demócrata-cristianos chilenos y volvió a proponer la teoría de los "opuestos extremismos". Según él, en realidad, habían sido los socialistas y el Movimiento de Izquierda Revolucionaria (MIR) los que rechazaron el acuerdo con el PDC y, con su extremismo, alimentaron "el aventurismo" de los grupos de extrema derecha como Patria y Libertad; y era a ellos, por consiguiente, a quienes había que imputar las mayores responsabilidades del desastre ${ }^{47}$. Al partido homólogo, en cambio, adjudicaba los errores de haberse aliado con los partidos de derecha sin denunciar "las responsabilidades en el plano de la estrategia de la tensión", y de no haber evaluado más profundamente

"los límites que se ponían a una oposición que fue sin duda dura, pero que se refería al mismo tiempo y más puntualmente, a los peligros involutivos implícitos en la situación. Pero se equivoca [...] quien imagine por parte nuestra una condena contra los demócrata-cristianos chilenos" $"$.

Esta posición no convenció al Partido Socialista que, a pesar de ello, mostró aprecio hacia la DCI por haber "tomado distancia de su hermana chilena". Elogiando la acción y la "ilimitada" confianza de Allende en los principios democráticos, Luigi Mariotti llevó adelante una durísima crítica hacia la democracia cristiana chilena (y, en especial, de Frei), a quien culpó de haberse "prestado al juego económico de potentes fuerzas internacionales [...] aliándose con la derecha facista" "49. La interpelación socialista advertía, además, sobre las posibles consecuencias de los hechos chilenos en la política italiana, e invitaba a sacar de aquella trágica experiencia un estímulo para volver a lanzar - profundizando la acción de reformas - la fórmula del centro-izquierda en Italia ${ }^{50}$.

\footnotetext{
${ }^{45}$ Ruggero Orfei, "Il colpo di stato dei militari allo specchio della politica italiana", Politica Internazionale, n. 10 , octubre de 1973, p. 44.

${ }^{46}$ Luigi Guarnieri - Maria Rosaria Stabili, "Il mito politico dell'America Latina negli anni Sessanta e Settanta", cit. p. 239.

${ }^{47}$ Atti parlamentari, Camera dei Deputati, VI Legislatura, 1973, Sesión del 26 de septiembre, p. 9171.

${ }^{48}$ Ibid. Es necesario resaltar, sin embargo, que al iniciar el discurso, sin nombrar a los demócratacristianos chilenos, Piccoli había hablado de "ingenuidad de aquellas fuerzas" que habían confiado en la intervención de los militares en lugar de comprometerse para una solución política (ivi, p. 9168).

49 Ivi, p. 9154.

${ }^{50}$ Es oportuno recordar que en Italia aquellos eran todavía los años de los gobiernos de centro-izquierda, o sea, basados en la alianza entre las fuerzas políticas de centro y el partido socialista. Además la intervención de Mauro Ferri, en nombre del Partido Socialista Democrático Italiano (PSDI), retomaba a grandes rasgos la del colega del PSI (ivi, pp. 9156-9160).
} 
La derecha italiana, obviamente, no compartió esta interpretación; es más, el llamado que venía de Chile tenía el intento de apelar a los demócrata-cristianos para que finalmente se encaminasen hacia la dirección opuesta a la indicada por los socialistas. En el Parlamento, el MSI consideró necesario el golpe con el objetivo de pacificar el País, aunque tuvo como efecto colateral el "sacrificio de la libertad". Al caso chileno bien se podía aplicar la fórmula de renunciar a toda responsabilidad moral para salvaguardar "el orden". Sin embargo, lo que más se evidenciaba de la interpelación del MSI era un duro ataque a la DC italiana y, en particular, un juicio despreciativo por su oportunismo, el cual se expresaría, según el MSI, en desaprobar la acción de los amigos chilenos, por cálculos políticos contingentes y para salvaguardar la estabilidad de la mayoría de gobierno. Dirigiéndose a los diputados demócrata-cristianos, el diputado Ernesto De Marzio afirmó, en efecto:

"¡Debieran pensarlo antes, cuando estaban en contacto con Frei, cuando estaban en contacto con la democracia cristiana chilena! ¿Es verdad o no, que la democracia chilena, que está unida a la democracia cristiana italiana no solo por vínculos ideológicos y políticos, informó constantemente, hasta la vigilia del golpe de Estado, sobre lo que sucedía en Chile? ¿La informó de sus preocupaciones sobre el posible golpe de estado de las izquierdas y de la imposibilidad de llegar a la colaboración con Allende? ¿Es verdad que la democracia cristiana italiana declaró que compartía aquellas preocupaciones y que aprobaba la línea de conducta de la democracia cristiana chilena? Y, para no ponerse en conflicto con los socialistas, para no ponerse en conflicto con los comunistas, ¿cómo pueden Ustedes renegar a sus amigos, los que han combatido una dura batalla durante tres años, en un País que estaba en condiciones difíciles?",.

No muy distinto fue el examen del Partido Liberal Italiano, cuya posición en la sala fue expresada por Vittorio Badini Confalonieri. Éste, anunciando que solo quería pedir al gobierno "aclaraciones", consideró Allende responsable "de la ruina política, económica y social" que había de hecho provocado el golpe, y después se lanzó contra los demócratacristianos chilenos - que habían mantenido "sobre el golpe de Estado un silencio de complicidad o, a decir lo menos, de tácita aprobación" - y sobre todo contra los demócratacristianos italianos, responsables de ofrecer, con su apoyo a Frei hasta poco antes del golpe, la oportunidad a los partidos de izquierda de instrumentalizar los eventos chilenos con objetivos de política nacional $^{52}$.

La evaluación del Partido Comunista tuvo un corte totalmente opuesto por lo que concierne el juicio del líder socialista chileno y de la acción del ejecutivo allendista, pero sustancialmente similar, en mérito a la conducta de los demócrata-cristianos chilenos (con la excepción de la corriente de izquierda de la que elogiaba el sentido de responsabilidad, la búsqueda del diálogo y el rechazo de soluciones de fuerza). La crítica era dirigida sobre todo contra la DC italiana, acusada implícitamente de ser corresponsable. Tras haber subrayado la "traición" de los generales, pero sobre todo de Frei ${ }^{53}$, Giancarlo Pajetta fustigaba al partido de la mayoría relativa, acusándolo de haberse separado solo a posteriori de la conducta del PDC 54

Indiferente a los ataques provenientes de la bancada opositora y con la moderación que lo distinguía, Aldo Moro, a quien correspondía el derecho de réplica del gobierno, en su

\footnotetext{
${ }^{51}$ Ivi, p. 9184.

52 Ivi, p. 9167.

53 Ivi, p. 9162.

${ }^{54}$ Ivi, p. 9163
} 
intervención antes de todo expresó el pésame por la muerte de Allende, que había "testimoniado con firmeza, hasta el sacrificio de la vida, su fe en la libertad y en el progreso de su pueblo" 55 ; después, recordó que ya el día siguiente el golpe había condenado las violaciones de los principios democráticos y el uso de la violencia ${ }^{56}$. Finalmente, y a pesar de no querer entrar en el mérito de las evaluaciones políticas que, según lo dicho, debían ser hechas por los partidos, el ministro de Relaciones Exteriores no pudo evitar de evidenciar que

"las dificultades encontradas en la economía y en la misma organización social de Chile [...] no pueden ser usadas para justificar la intervención de los militares [...] este golpe de estado es muy grave y lleva consigo siniestros presagios" ${ }^{~}$.

Sin embargo, la condena del golpe no se tradujo en un acto de ruptura con la junta militar, como había solicitado la izquierda política. En su discurso en la Cámara de Diputados, y en las declaraciones de las semanas siguientes, Moro eligió una estrategia de "espera" en cuanto a las relaciones diplomáticas con el nuevo régimen chileno, estrategia que dejaba a Italia la puerta abierta para cualquier desarrollo futuro, pero que, entre líneas, hacía entrever su preferencia por la conservación de las relaciones. Una "espera", además, que era debida también al anhelo que se pudiese proceder con una iniciativa conjunta en ámbito europeo. De hecho, Moro recordó que, en el ámbito de la CEE, Francia, Inglaterra, Alemania Federal y Dinamarca ya habían deliberado mantener las relaciones diplomáticas en base al principio (apoyado particularmente en Paris) que los que se reconocen son los Estados y no los gobiernos que son llamados a guiarlos paso a paso; y agregando que "el contacto diplomático, útil para la protección de los intereses y además para favorecer la evolución democrática o de todas maneras la atenuación del rigor de la represión, no significa de ninguna manera la aprobación del método de la violencia y del hecho consumado" ${ }^{58}$. Algunos días después, también Flaminio Piccoli, al contestar a las preguntas de los periodistas italianos que le pedían juicios sobre las quejas de los principales representantes de la comunidad italiana en Chile (por la mayoría a favor del golpe), compartía la posición de Moro, insistiendo en que

"hace falta evaluar el problema de la toma de conciencia de la situación - tal y como lo hicieron muchos otros Países - en base [...] a la tutela de los intereses de [...] nuestros connacionales y [...] a la posibilidad de una intervención efectiva que pudiese manifestarse, mediante pasos oficiales, contra las persecuciones y las represiones"59.

Hay más de un indicio de esta orientación en las comunicaciones que la embajada chilena en Italia envió a Santiago en los primeros meses post-golpe. Ellas documentan primero, la convicción que el reconocimiento se llevaría a cabo tras el ya tan mencionado debate en el Parlamento y una vez disminuida la presión de la prensa ${ }^{60}$; después, que esta decisión podría

\footnotetext{
55 Ivi, pp. 9186-9187.

56 Ivi, p. 9187. Para el comunicado de la Farnesina véase Il Popolo del 13 de septiembre de 1973.

${ }^{57}$ Atti parlamentari, Camera dei Deputati, VI Legislatura, 1973, Sesión del 26 de septiembre, p. 9188.

58 Ibid.

${ }^{59}$ Archivio Storico dell'Istituto Sturzo, Fondo Flaminio Piccoli, busta 16, fascicolo 176, “Comunicato stampa", 2 de octubre de 1973.

${ }^{60}$ Cfr. Archivo del Ministerio de Relaciones Exteriores - desde ahora AMRE - Embajada chilena en Roma a Ministerio de Relaciones Exteriores, Telex cifrado n. 72, 26 de septiembre de 1973; y Cable cifrado n. 76, 28 de septiembre de 1973.
} 
provocar efectos negativos a la estabilidad política italiana ${ }^{61}$ e "incluso la ruptura de la coalición de centro-izquierda y la consiguiente caída del gobierno Rumor" "62 . A partir del mes de noviembre, entonces, el tema de las relaciones con la junta militar fue, según parece, estrechamente asociado, para el ejecutivo italiano, al problema de los tantos chilenos en fuga desde la represión, que se habían refugiado en la sede de la embajada italiana en Santiago ${ }^{63}$. De hecho, la indecisión de Palazzo Chigi llevó a que, al poco tiempo, se suspendiesen las relaciones diplomáticas con Chile, pero sin que ellas fuesen formalmente interrumpidas, y provocó el aislamiento en el plano diplomático europeo ${ }^{64}$.

\section{La tímida reconciliación}

Hay que señalar, sin embargo, que para el ejecutivo, por una parte, debido a las críticas de los aliados socialistas, y por otra, a las presiones comunistas, y con la fuerte movilización social en acto en el país, no fue fácil moverse, pero sobre todo a causa de las tensiones internas de la DCI, presionada entre la debida condena oficial del golpe y la voluntad de no debilitar sobre manera las relaciones con la democracia cristiana chilena, ayudada y apoyada activamente desde $1962^{65}$. Es también en este contexto que se enmarca la carta que Eduardo Frei Montalva envió a Mariano Rumor el 8 de noviembre de $1973^{66}$. A pesar de que fuese escrita especialmente para informar a la internacional demócrata-cristiana sobre el desarrollo de la situación chilena, además ella pretendía restablecer con los amigos italianos las relaciones deterioradas justo a causa del golpe. Reafirmando conceptos ya expresados muchas

${ }^{61}$ AMRE, Embajada chilena en Roma a Ministerio de Relaciones Exteriores, Cable cifrado n. 80, 1 de octubre de 1973.

${ }^{62}$ AMRE, Embajada chilena en Roma a Ministerio de Relaciones Exteriores, Cable cifrado estrictamente confidencial n. 83, 5 de octubre de 1973.

63 Véase, solo como ejemplo, AMRE, Embajada chilena en Roma a Ministerio de Relaciones Exteriores, Telex estrictamente confidencial n. 132, 23 de noviembre de 1973. Es necesario recordar que desde el 11 de septiembre de 1973 hasta la llegada a Santiago de Tomaso de Vergottini en el mes de diciembre (jefe de la misión italiana hasta el 1984), la embajada italiana estuvo a cargo de Piero De Masi, ya que el embajador de Italia en Chile, Norberto Behman D’Elmo, se encontraba en Roma el día del golpe. Hay tres reconstrucciones de lo que hizo la embajada italiana en Chile: el libro de de Vergottini (Cile: diario di un diplomatico (1973-1975), Roma, Koinè Nuove Edizioni, 2000), que resulta ser el más completo, puntual y rico de informaciones; el de De Masi (Santiago. 1 febbraio 1973 - 27 gennaio 1974, Acireale-Roma, Bonanno, 2013) publicado 40 años después del golpe chileno; finalmente, el libro, menos convincente y demasiado anecdóctico, de Emilio Barbarani (Chi ha ucciso Lumi Videla? Il golpe di Pinochet, la diplomazia italiana e i retroscena di un delitto, Milano, Mursia, 2012). Merece la pena subrayar que, cuando en noviembre de 1973 el encargado de negocios de la embajada chilena dio la noticia del posible nombramiento de de Vergottini como jefe de la misión italiana en Chile, se preocupó también de decir que se trataba de un demócrata-cristiano de la corriente "de derecha" (AMRE, Embajada chilena en Roma a Ministerio de Relaciones Exteriores, Aerograma Confidencial n. 73, 17 de noviembre de 1973).

${ }^{64}$ Cfr. Luigi Vittorio Ferraris (a cura di), Manuale della politica estera italiana 1947-1993, Roma-Bari, Laterza, 1996, pp. 309-310, pero véase también Annuario dell'Istituto Affari Internazionali, 1974-75, p. 631. La línea escogida por el gobierno italiano fue confirmada en el Parlamento algunos meses después por el subsecretario de Relaciones Exteriores Mario Pedini (Atti parlamentari, Senato della Repubblica, VI legislatura, 1974, Sesión del 13 de febrero, p. 12708). Véase finalmente el comentario "Immutata la posizione del governo contro la giunta cilena”, Politica Internazionale, n. 2, febrero de 1974, pp. 25-26; y "Dissenso del Governo per il «golpe» in Cile", Il Popolo, 14 de febrero de 1974.

${ }^{65}$ En las páginas que siguen retomo algunas reflexiones ya adelantadas en "Il governo italiano e la DC di fronte al golpe cileno", Nuova Storia Contemporanea, n. 2, marzo-abril 2008. pp. 87-110.

${ }^{66}$ La versión original se encuentra en el Centro de documentación Fundación Frei. Una reproducción integral se encuentra en el libro a cargo de Sofía Correa et al., Documentos del siglo XX chileno, Santiago, Editorial Sudamericana, 2001, pp. 413-427. Cabe señalar que la carta fue enviada también al papa Paolo VI (cfr. CFF, Carta de Eduardo Frei a Paolo VI, noviembre de 1974 y la respuesta, en nombre del pontífice, del nuncio apostólico Sótero Sanz Villalba del 11 de diciembre, Correspondencia Internacional, C.C.-2.2/IT). 
veces en los tres años anteriores ${ }^{67}$ y retomados en varios diarios de inspiración demócratacristiana $^{68}$, el ex presidente de la República pretendía, de hecho, recordar a los demócratacristianos italianos que siempre los había informado sobre la evolución política nacional desde el ascenso al poder por parte de Allende hasta el 11 de septiembre de $1973^{69}$. Deseoso, además, de confrontar la versión que en Italia (y en Europa) estaban difundiendo - o empezando a difundir - los partidos de izquierda y los principales exponentes del grupo de los disidentes (en particular Leighton), en la carta Frei justificaba su conducta y la de su partido en ocasión del golpe de Estado y desmentía toda colaboración con los militares.

“A nuestro juicio la responsabilidad integra de esta situación [...] corresponde al régimen de la Unidad Popular instaurado en el país [...] la Democracia Cristiana chilena puede decir ante el mundo que una vez más dio un ejemplo de honradez democrática y de lealtad con sus principios [...] Las Fuerzas Armadas - estamos convencidos - no actuaron por ambición. Más aún, se resistieron largamente a hacerlo. Su fracaso ahora sería el fracaso del país y nos precipitaría en un callejón sin salida. Por eso los chilenos, en su inmensa mayoría, más allá de toda consideración partidista, quieren ayudar porque creen que ésta es la condición para que se restablezca la paz y la libertad en Chile",70.

${ }^{67}$ De hecho, la carta parte enumerando los créditos democráticos del PDC chileno, incluyendo su papel en la derogación de la "Ley Maldita", la forma democrática de su gobierno entre 1964 y 1970 con amplias garantías para los opositores, el establecimiento de relaciones diplomáticas con la URSS y otros países socialistas. Como parte de esta conducta democrática, se destaca especialmente el haber apoyado en el Congreso el triunfo de Allende en 1970. También la oposición ejercida por el PDC a Unidad Popular entre 1970 y 1973 se caracteriza como democrática. La clave para responsabilizar al gobierno de Allende y a la izquierda del quiebre de la democracia está en la insistencia en su carácter de gobierno de minoría que, según Frei, no accedía a negociar y trataba de imponer su línea a toda costa, incluso violando la legalidad. A ello se agregan sobre todo dos líneas de crítica: el colapso económico del País y el ingreso de armas para preparar un autogolpe.

${ }^{68}$ Como ejemplo, véase el comentario a las elecciones parlamentarias de marzo de 1973 firmado por Dedalo Dati ("Il futuro del Cile sempre nelle mani della DC", D.C. Internazionale. Notizie, documentazioni e commenti sulla presenza dei democratici cristiani nel mondo, n. 1/73, marzo de 1973, pp. 6-8,), donde se evaluaba el actuar del gobierno de la U.P. "un socialismo peligrosamente liberticida, muy a menudo aplicado al margen de las leyes y de la Constitución si no hasta fuera de ellas. Reformismo que, no raras veces ha dado, en estos dos últimos años, la neta sensación de que Chile estuviera precipitando hacia una dictadura de clara matriz marxista"; mientras que, sobre la actuación de la DC chilena, se subrayaba que había hecho una "oposición firme, pero sin excesos".

${ }^{69} \mathrm{~A}$ tal propósito, véanse las cartas - todas en CFF, Correspondencia Internacional CC-2-D y Correspondencia Internacional CC-2.1 - del 27 de junio y del 16 de septiembre de 1971, del 27 de octubre de 1972, del 5 de abril de 1973, enviadas por Eduardo Frei a Angelo Bernassola, del 31 de agosto de 1971 a Paolo Emilio Taviani; del 23 de mayo de 1973 a Mariano Rumor, donde se reiteran las referencias a la "dramática" situación vivida por el País. Hay que señalar además que Frei viajó a Italia varias veces desde el fin de su mandato presidencial casi hasta el momento del golpe de Estado, y que en ocasión del XII congreso de la DC italiana declaró que su partido estaba enfrentando a un gobierno que "está llevando el País hacia una dictadura totalitaria y que ha destruido, en dos años y medio, la economía del País de una manera inimaginable" (CFF, Intervención de Eduardo Frei durante el desarrollo del XII Congreso del Partido Demócrata Cristiano de Italia, 6 de junio de 1973, Labor Internacional Efin -1-D).

${ }^{70}$ Vale la pena señalar que menos de veinte días después, en una carta a Valdés, Felipe Amanategui, miembro de la última dirección nacional que había emitido el documento del 12 de septiembre, hacía notar sarcásticamente como Frei fuera promotor, en oposición a Tomic, de una línea estratégica basada en el "éxito del Gobierno militar en sus objetivos; pacificación y reordenamiento social, político y económico de Chile para que, cumplida su tarea, las Fuerzas Armadas, devuelvan el poder al pueblo". Según él, se trataba de una postura ingenua y "creer que quienes detentan el poder estarán dispuestos a devolverlo por su propio desinterés, por su heroísmo, desprendimiento u otros motivos igualmente altruistas, no solo 
A pesar de ello, Frei no logró convencer a Rumor y obtener la solidaridad del partido italiano, como se lee en la correspondencia privada con Angelo Bernassola, del que se hablará más adelante. Según Cristián Gazmuri el problema de fondo - del que nació el fastidio de Rumor y de otros exponentes de la DCI - consistió en el hecho de que a los ojos de los demócrata-cristianos europeos e italianos el relato de los eventos chilenos narrados por el grupo de disidentes del PDC que circulaban por Europa "era una verdad más "creíble","71. Por cierto, estos últimos no se quedaron de brazos cruzados y utilizaron todos los medios a su disposición para desmentir el actuar de los dirigentes del partido (en particular el del ex presidente de la República) y para manifestar su rechazo a la toma del poder por parte de los militares. Además de las declaraciones públicas, la confirmación llega a través de los documentos reservados, como es el caso de una carta que Fuentealba envió pocos días después al mismo presidente de la UMDC:

"Tengo conocimiento de que altos personeros demócratacristianos chilenos, se han dirigido a ud. tratando de justificar la vacilante y débil actitud que nuestro Partido tuve con ocasión de los últimos acontecimientos. Esas personas, que siempre me han combatido, hasta el extremo de jugarse enteros para sacarme de la dirección del Partido, a fin de que ésta adoptara una actitud política de absoluta intransigencia frente al gobierno de la U.P. [...] Pero lo que esas personas olvidan o callan intencionalmente, es que la Directiva que presidí, y personalmente, fuimos siempre absolutamente contrarios a una solución de fuerza, a un golpe o a un pronunciamiento militar que otros, en cambio, veían siempre con buenos ojos y estimulaban directamente o indirectamente [...] Yo sé que los dirigentes italianos son lo suficientemente inteligentes para no dejarse engañar [...] Hoy, en este momento, nadie en el Partido, puede dar opiniones políticas a nombre del partido. Sus organismos están paralizados"

La dificultad de Frei y de otros exponentes de primer plano del PDC en romper las resistencias de los demócrata-cristianos italianos, están, en cambio, claramente atestiguadas por las numerosas críticas expresadas por el mismo líder chileno entre los años 1974-75 y, sobre todo, por el silencio de la DCI. No es un caso que Bernassola escribiese a Frei, solo dos meses después y en relación a la carta enviada a Rumor el 8 de noviembre, desmintiendo un juicio negativo sobre el actuar de la democracia cristiana italiana y expresando comprensión por el "drama" que el partido chileno estaba viviendo ${ }^{73}$. Bernassola también comunicaba que la conducta de su partido era debida al hecho de que "tras el Congreso de junio pasado, muchas cosas y personas han cambiado y no siempre los «nuevos» conocen los hechos y los antecedentes de situaciones politicas de otros países, siendo inexcusable su ignorancia", pero sobre todo:

"Lo que tengo a precisar [...] es que diversas cosas han ocurrido en cierto modo para evitar grandes problemas o complicaciones internas. Tal y como aquí es unánime el rechazo a toda acción violenta tanto de los marxistas como de los militares, también es

es desconocer la realidad humana, sino además renunciar a actuar como político" (AHGV, Carta de Felipe Amanategui a Gabriel Valdés, 26 de noviembre de 1973).

${ }^{71}$ Cristián Gazmuri, Eduardo Frei Montalva y su época, $2^{\circ}$ vol., cit. p. 869.

72 AHGV, Carta de Renán Fuentealba Moena a Mariano Rumor, 21 de noviembre de 1973.

${ }^{73} \mathrm{CFF}$, Carta de Angelo Bernassola a Eduardo Frei Montalva, 10 de enero 1974, Correspondencia Internacional CC-2-D. 
unánime el sentido de solidaridad y de cercanía de los d.c italianos con los amigos d.c. chilenos. Es verdad que también recientemente, se han cometido errores en el plano táctico, sin embargo esto no debe resquebrajar la amistad de fondo entre nosotros. Éste es el sentimiento de sus amigos italianos y no cambiará [...] Es probable que, en algunos meses, otros y yo viajemos a Chile también para demostrar que no consideramos definitivo este estado de cosas y este régimen, que estamos cerca de Ustedes en todo esfuerzo hecho a favor de la libertad y de la democracia".

Pidiendo paciencia, ocultándose tras las dificultades políticas internas y definiendo los errores cometidos por los demócrata-cristianos chilenos exclusivamente como "tácticos", Bernassola logró entablar de nuevo sus relaciones con Frei y la mayoría de su partido y, sobre todo, convenció al líder chileno de mirar hacia adelante. Este último respondió dos meses después ${ }^{74}$ expresando su complacencia por la carta ("tenía la impresión de que todos mis amigos italianos habían dejado de existir"), pero al mismo tiempo evidenciaba, sin nombrarlo, que Rumor ni siquiera le comunicó que la había recibido ("Esto se hace aún con las personas más insignificantes"). Sin embargo a pesar de todo, según él, ese episodio no podía modificar

"mi afecto por quienes han sido tan expecionales amigos [...] Durante tres años fui muy franco para decir lo que iba a pasar en Chile. Sin embargo ahora estimen que poco menos ha sido responsabilidad nuestra la catástrofe de nuestro país. No lo entenderé nunca [...] Si bien algunos no han tenido confianza en nosotros, nosotros seguimos teniendo confianza en Uds. y seguimos con el más vivo interés todo lo que en Italia ocurre, y también - porqué no decirlo - con una tremenda preocupación, ya que siempre hemos visto en PDC italiano una firme columna de todo el movimiento de la Democracia Cristiana mundial. Yo siempre he comprendido la posición de la DC italiana, pues creo que Uds. Tienen que mirar primero sus problemas internos. El Partido Comunista usa el caso chileno para atacar y chantajear a la DC italiana. Su dualismo es evidente y nosotros lo sufrimos en toda su extensión. Ningún DC chileno estaba comprometido en el golpe y el actual gobierno es cada vez más hostil a la Democracia Cristiana en Chile" ${ }^{, 75}$.

Poco más de un año después ${ }^{76}$ Frei reiteraba:

\footnotetext{
${ }^{74} \mathrm{CFF}$, Carta de Eduardo Frei Montalva a Angelo Bernassola, 5 de marzo de 1974, Correspondencia Internacional CC-2-2-IT.

${ }^{75}$ La insistencia de Frei de que "ningún DC chileno estaba comprometido en el golpe" no logra imponerse en la opinión pública italiana por encima de un aspecto ya conocido también en Italia, es decir, la colaboración con el gobierno militar por parte de exponentes de su partido y anticipada por Aylwin a Valdés en la carta ya mencionada del 16 de octubre (cfr. Cristián Gazmuri, Eduardo Frei Montalva y su época, cit. p. 869). Si bien Aylwin hable de cuadros técnicos e incluso esta participación fuera pronto retirada por el PDC con la expulsión de aquellos que se quedaban, la imagen queda instalada. Un resumen de las restricciones a las cuales fue sometido el partido hasta mediados de 1975 se encuentra en el segundo número de la revista, difundida entre los partidos demócrata-cristianos latinoamericanos, Informaciones Demócratas Cristianas (septiembre de 1975, pp. 1-31).

${ }^{76}$ En ese año, merece la pena recordarlo, el PDC ya estaba prácticamente en la oposición y había abrazado por completo la causa de los derechos humanos; y el propio Frei, tachado por los militares como el "Kerensky chileno", estaba publicando El mandato de la historia y las exigencias del porvenir (Santiago, Editorial del Pacífico, 1975), un libro abiertamente opositor a la junta militar.
} 
"aún cuando la DC italiana ha demostrado tanto desprecio por la Democracia cristiana chilena, yo sigo creyendo que es fundamental para nuestra causa que Uds. tengan éxito. Yo creo que el tiempo dirá muchas cosas. Portugal es un buen ejemplo [...] He visto con qué energía la DC italiana ha defendido las libertades en Portugal y en especial, los demócratacristianos perseguidos. Sin embargo, no he visto la misma confianza y el mismo ardor para con nosotros en Chile, seguramente porque somos más pequeños y estamos más lejanos ${ }^{77}$.

A pesar del resentimiento que todavía manifestaba el líder demócrata-cristiano chileno, los tiempos ya estaban maduros para la reconciliación. En ocasión de una visita de Bernassola a Chile, Rumor, en aquel momento Jefe del Ministerio de Relaciones Exteriores ${ }^{78}$, envió una breve carta a Frei, en la que manifestaba "nuestra solidaridad" e implícitamente invitaba a dejar de lado los desacuerdos ${ }^{79}$. El ex presidente chileno contestó de inmediato, deseando que "aclarado muchos hechos, se mantenga la amistad, la solidaridad y la confianza recíproca" Entonces, el desacuerdo nacido en ocasión del golpe se superaba, si bien el 11 de septiembre dejó heridas nunca totalmente saneadas ${ }^{81}$. Los dos partidos volvieron, de hecho, a colaborar, pero manteniendo como principal horizonte el fortalecimiento de la internacional demócratacristiana $^{82}$.

Se puede concluir evidenciando la profunda ambigüedad que caracterizó el comportamiento de la DC italiana y, por tanto, del gobierno, en particular del ministerio de Relaciones Exteriores, sobre todo en los meses que siguieron al golpe. Ambigüedad que, en el caso de la primera, se superaría solo a partir del año 1975, cuando las relaciones con el PDC volvieron a normalizarse, aunque el reencuentro entre los dos partidos se completó solo con la reconciliación interna de la DC chilena. Por lo que atañe a las relaciones diplomáticas entre

${ }_{77}$ CFF, Carta de Eduardo Frei Montalva a Angelo Bernassola, 25 de abril de 1975, Correspondencia Internacional CC-2-D.

78 Desde el 1974 al 1976 en el IV y V Governo Moro. Hay que hacer notar que el $1^{\circ}$ de abril Rumor había recibido por parte de de Vergottini, una larga relación confidencial (titulada "Il regime militare cileno") en la cual se reconstruía también la conducta de la democracia cristiana chilena durante el golpe. Para el jefe de la misión de la embajada italiana en Chile, el PDC, contrastando el gobierno Allende, se había simplemente dividido sobre los "métodos de lucha". De Vergottini reconocía sin embargo que, después del 11 de septiembre, dirección y base habían avalado "el operado de la Junta", mientras la izquierda había manifestado públicamente su propio desacuerdo; señalando, finalmente, que "a medida que el nuevo gobierno revelaba su verdadera cara [...] también dirección y base del PDC empezaron a cambiar de actitud. En el verano de 1974, Patricio Aylwin delineaba la posición del partido con la fórmula «independencia activa y crítica», que excluye por un lado la resistencia y, por el otro, la colaboración" (Archivio Centrale dello Stato - de ahora en adelante ACS - Fondo Consigliere diplomatico della Presidenza del Consiglio dei Ministri, II parte, 1964-1985, sobre 37, Relación confidencial de Tomaso de Vergottini al ministro de Relaciones exteriores Mariano Rumor, $1^{\circ}$ de abril de 1975).

${ }^{79}$ CFF, Carta de Mariano Rumor a Eduardo Frei, 17 de mayo de 1975, Correspondencia Internacional, C.C.2.2/IT.

${ }^{80}$ CFF, Carta de Eduardo Frei a Mariano Rumor, 23 de mayo de 1975, Correspondencia Internacional, C.C.$2.2 /$ IT.

${ }^{81}$ Relevante en este sentido es una carta que Frei envió a finales de diciembre del 1974 al otro gran líder demócrata cristiano latinoamericano, Rafael Caldera, presidente de Venezuela desde el 1969 a 1974, en la que se quejó mucho de la actitud de los demócrata-cristianos italianos y europeos, acusándolos sin tapujos de "cobardía" (CFF, Carta de Eduardo Frei a Rafael Caldera, 9 de diciembre de 1974, Correspondencia Internacional CC-2-D.).

${ }^{82}$ Los documentos custodiados en el archivo de la Fundación Frei son muchos - imposible de incluír en esta ocasión - y confirman que en los siguientes años las relaciones entre Frei y Rumor tuvieron que ver casi exclusivamente con la UMDC. 
Italia y Chile, la falta de claridad dejaría lugar a una especie de ficción: oficialmente quedaron estancadas hasta el retorno de la democracia, sin dejar, sin embargo, que eso impidiera las relaciones que se seguían teniendo, si bien con un volumen de negocios reducido con respecto al pasado, a nivel comercial y, más generalmente, a nivel económico ${ }^{83}$. En efecto, a pesar de las escaramuzas de los primeros meses posteriores al golpe y en un contexto de reiteradas tensiones diplomáticas, originadas sobre todo por la cuestión de los refugiados acogidos por la embajada italiana en Santiago, acerca de la cual no podemos ahondar por razones de espacio ${ }^{84}$, el Ejecutivo mantuvo siempre separados el plano político-ideológico del económico. La asociación entre dimensión política y dimensión diplomática significó, sin embargo, muchos dolores de cabeza para Roma y, sobre todo, para los representantes diplomáticos italianos en Chile, no obstante en mayo de 1981 ambos Países procedieron a reconocer oficialmente a los respectivos encargados de negocios, el italiano Tomaso de Vergottini y el chileno Mariano Fontecilla.

Es lo que señaló, precisamente poco antes de este paso oficial, en marzo de aquel año, el mismo de Vergottini en una relación enviada al ministro italiano de Relaciones Exteriores Emilio Colombo, documento que merece ser citado en algunos pasos, porque sintetiza eficazmente algunos de los ejes que se han intentado analizar en este ensayo. Después de siete años, así escribía el jefe de la misión italiana,

"Vale la pena reflexionar sobre el pasado, saber si fue bueno o malo, para nuestro Gobierno, manifestar una actitud de rechazo político [...] El caso chileno se transformó para nosotros [...] en un acontecimiento de política (interna) [...] Ahora, a siete años de distancia, se intenta recoser el tejido separando lo político de lo diplomático. Pero no es fácil [...] Hay también que reconocer que el régimen chileno, justo cuando parece ofrecer una oportunidad, en seguida retracta. Por ejemplo, estimulado por un Reagan intento a maquillar los regímenes latinoamericanos a los que destina su apoyo, Pinochet ofrece al pueblo chileno una nueva Constitución, que por lo demás, se revela construída a medida para la oligarquía [...] Las ceremonias a las que he asistido no tienen nada de provisorio, o de transitorio; al contrario, se parecen a una coronación de tipo napoleónico del Presidente "más omnipotente" de la historia de Chile [...] Por el momento, el camino escogido no parece el más idóneo para reconducir a Chile a su secular tradición democrática y legalista. Pero ésta es la constatación política, mientras que, para nosotros, es preciso separar lo político de lo diplomático" ${ }^{" 85}$.

\footnotetext{
${ }^{83}$ Véase a tal propósito la carta enviada por el diputado Antonio Falconio al presidente del Consiglio dei ministri Arnaldo Forlani, en mayo de 1981, en la que se apoyaba la causa de la regularización de las relaciones diplomáticas, para aumentar los intercambios comerciales con Chile y para "tranquilizar y estimular a nuestra numerosa y calificada comunidad italiana” (ACS, Fondo Consigliere diplomatico della Presidenza del Consiglio dei Ministri, II parte, 1964-1985, sobre 37, 6 de mayo de 1981).

${ }^{84}$ La situación, iniciada el día después del Golpe, se concluyó el 8 de abril de 1975 con la salida del País del último grupo de refugiados (en total la Embajada italiana acogió a 676 de los cuales 531 llegaron a Italia). Para un balance véase la relación confidencial enviada por De Vergottini al ministro Rumor en ACS, Fondo Consigliere diplomatico della Presidenza del Consiglio dei Ministri, II parte, 1964-1985, sobre 37, 21 de abril de 1975.

${ }^{85}$ ACS, Fondo Consigliere diplomatico della Presidenza del Consiglio dei Ministri, II parte, 1964-1985, sobre 37, 19 de marzo de 1981.
} 


\section{Bibliografía}

Amorós Mario, Allende. La biografía, Barcelona, Ediciones B, 2013

Arbøl Niels, I democristiani nel mondo, Milano, Edizioni Paoline, 1990

Aylwin Azócar Patricio, El reencuentro de los Demócratas. Del Golpe al Triunfo del NO, Santiago, Ediciones B, 1998

Barbarani Emilio, Chi ha ucciso Lumi Videla? Il golpe di Pinochet, la diplomazia italiana e i retroscena di un delitto, Milano, Mursia, 2012

Bertolini Franca -Hermans Frieda, La DC in Cile, Milano, Mazzotta, 1974

Corghi Corrado, L'ideologia democristiana e l'internazionale DC, Milano, Mazzotta, 1974

De Masi Piero, Santiago. 1 febbraio 1973 - 27 gennaio 1974, Acireale-Roma, Bonanno, 2013

De Vergottini Tomaso, Cile: diario di un diplomatico (1973-1975), Roma, Koinè Nuove Edizioni, 2000

Di Salvo Pino (a cura di), Cile. Una lezione. Documenti della sinistra democristiana cilena, Roma, La Tartaruga, 1974

Donoso Pacheco Jorge (comp.), Tomic, testimonios, Santiago, Editorial Emisión, 1988

Donoso Pacheco Jorge - Dunlop Echavarría Grace, Los 13 del 13. Los DC contra el golpe, Santiago, RIL Editores, 2013

Ferraris Luigi Vittorio (a cura di), Manuale della politica estera italiana 1947-1993, Roma-Bari, Laterza, 1996

Fleet Michael, The Rise and Fall of Chilean Christian Democracy, Princeton, Princeton University Press, 1985

Gazmuri Cristián, Eduardo Frei Montalva y su época, II tomos, Santiago, Aguilar, 2000

Giovagnoli Agostino, Il partito italiano. La Democrazia cristiana dal 1942 al 1994, Roma-Bari, Laterza, 1996

Giovagnoli Agostino - Del Zanna Giorgio (a cura di), Il mondo visto dall'Italia, Milano, Guerini e Associati, 2004

Hofmeister Wilhelm, La opción por la democracia. Democracia Cristiana y desarrollo político en Chile, 1964-1994, Santiago de Chile, Konrad Adenauer Stiftung, 1995

Lomellini Valentine, "Bisbigliando al «nemico»? Il Pci alla svolta del 1973, tra nuove strategie verso Washington e tradizionale anti-americanismo", Ricerche di Storia Politica, n. 1/2013, pp. 25-44.

Mainwaring Scott - Scully R. Timothy (eds.), La democracia cristiana en América Latina, México, Fondo de Cultura Económica, 2010

Mulas Andrea, Il Cile di Allende e la politica italiana: il compromesso storico, San Cesario di Lecce, Manni, 2005

Nocera Raffaele, "Il governo italiano e la DC di fronte al golpe cileno", Nuova Storia Contemporanea, n. 2, marzo-abril 2008. pp. 87-110 
Nocera Raffaele, "Dove non osò la diplomazia. Alcune riflessioni sull'internazionalismo democristiano e sulle relazioni italo-cilene, 1962-1970", Ricerche di Storia Politica, n. 1/2009, pp. $29-52$

Nocera Raffaele, "Las relaciones diplomáticas y político partidistas ítalo-chilenas durante el gobierno de Eduardo Frei Montalva", Historia, n. 42, vol. II, julio-diciembre de 2009, pp. $435-470$

Nocera Raffaele - Rolle Cruz Claudio (a cura di), Settantré. Cile e Italia, destini incrociati, Napoli, Think Thanks, 2010

Ortega Frei Eugenio, Historia de una alianza, Santiago, CED-CESOC, 1992

Papini Roberto, L'Internazionale DC. La cooperazione tra i partiti democratici cristiani dal 1925 al 1985, Milano, Franco Angeli, 1986

Santoni Alessandro, "Berlinguer, il compromesso storico e il caso cileno", Contemporanea, 3, julio de 2007, pp. 419-439

Santoni Alessandro, Il PCI e i giorni del Cile, Roma, Carocci, 2008

Subercaseaux Elizabeth, Gabriel Valdés, señales de historia, Santiago, Aguilar, 1998 2009

Ulianova Olga (ed.), Redes Políticas y militancias, Santiago, Universidad de Santiago,

Valdés Gabriel, Sueños y memorias, Santiago, Taurus, 2009

Recibido: 4 abril 2015 Aceptado: 4 junio 2015 